\title{
DIFFERENT PARAMETERIZATIONS FOR WIND VARIANCE APPLIED TO THE CONVECTIVE BOUNDARY LAYER GROWTH MODEL
}

\author{
André B. Nunes ${ }^{1}$, Prakki Satyamurty ${ }^{2}$, Haroldo F. de Campos Velho ${ }^{3}$, \\ Maria Eugenia S. Welter ${ }^{4}$ \\ ${ }^{1}$ Universidade Federal de Pelotas (UFPel), Brazil \\ ${ }^{2}$ Universidade do Estado do Amazonas (CESTU), Brazil \\ ${ }^{3,}{ }^{4}$ Instituto Nacional de Pesquisas Espaciais (INPE), Brazil \\ ${ }^{1}$ andre.nunes@ufpel.edu.br, ${ }^{2}$ saty.prakki@gmail.com \\ ${ }^{3}$ haroldo@lac.inpe.br, ${ }^{4}$ marowelter@gmail.com
}

\begin{abstract}
The turbulent kinetic energy (TKE) evolution is analyzed during the morning transition from the neutral stratification to fully convective boundary layer, using analytical spectral models. Parameterizations for wind variance are introduced into 3D spectral models. The TKE for these models has good agree agreement with LES.
\end{abstract}

\section{RESUMO}

A evolução da energia cinética turbulenta (ECT) é analisada durante a fase de transição matinal, usando modelos espectrais analíticos. Distintas parametrizações para a variância do vento são introduzidas nos modelos espectrais. A evolução da ECT para os modelos espectrais tem boa concordância com resultados da simulação de grandes vortices.

\section{INTRODUCTION}

This paper deals with evaluations for the TKE evolution during the transition from the nocturnal to morning boundary layer. The analysis is performed employing an analytical model to the dynamics of the TKE. Four theoretical spectral models (hereafter, M1, M2, M3, M4) are considered, with different parameterizations for the wind variance. The evolution for TKE spectra is compared with data from the Large-Eddy Simulation (LES) - see Moeng (1984). 


\section{SPECTRAL MODEL FOR THE CBL GROWTH}

A model for CBL growth is obtained by solving the dynamical spectral equation for the TKE, using the Heisenberg theory (Stanišić, 1988). Following Campos Velho (2003):

$$
\begin{aligned}
E(k, t)= & E_{0}(k) \exp \left\lfloor-k^{2}\left(v_{T}+v\right) t\right\rfloor \\
& +\frac{H(k)}{2 \mathrm{k}^{2}\left(v_{T}+v\right)}\left\{1-\exp \left[-k^{2}\left(v_{T}+v\right) t\right]\right\}
\end{aligned}
$$

where $E_{0}(k)$ is the $3 \mathrm{D}$ spectrum for the neutral layer, and the term $\mathrm{H}(\mathrm{k}) /\left(2 \mathrm{k}^{2} v_{\mathrm{T}}+v\right)$ is the $3 \mathrm{D}$ convective energy spectrum fully developed. The 3D spectrum is obtained from $1 \mathrm{D}$ spectra (Kristensen et al., 1989; Goulart et al., 2003; Nunes et al., 2010):

$$
E(k)=k^{3} \frac{d}{d k} \frac{1}{k} \frac{d F_{L}}{d k}+2 k^{4} \quad{ }_{0}^{k^{2}} s^{2} g(s) d s \quad \frac{14}{9} k^{4 / 3}{ }_{0}^{k^{2}} s^{2 / 3} g(s) d s
$$

where $F_{L}$ is the $1 \mathrm{D}$ spectrum in the longitudinal direction for convective and neutral layers, $\mathrm{s}=\mathrm{k}^{-2}$, and $\mathrm{g}(\mathrm{s})$ is a given function (Kristensen et al., 1989). Four spectra models, considering different parameterizations for velocity variances, are employed for comparison with LES:

(a) M1: parameterization presented by Kristensen's et al. (1989);

(b) M2: parameterization described by Degrazia et al. (1997);

(c) M3: parameterization described by Degrazia and Anfossi (1998) and Goulart et al. (2004);

(d) M4: employs the dissipation rate for M3-model, but using the velocity variance applied to M1-model. 


\section{RESULTS AND REMARKS}

Analytical models results are compared with LES outputs (Moeng, 1984). The numerical experiment is performed as follows: (a) the boundary layer starts with a convective boundary layer, up to the quasi-stationary state (QSS); (b) CBL is simulated by about 1 hour; (c) the decay of CBL is simulated (Nunes et al., 2010); (d) nocturnal period: neutral boundary layer is simulated by 2.5 hours; (e) the growth of the CBL is simulated increasing the surface heat flux from zero up to $0.24 \mathrm{Kms}^{-1}$, (f) finally, the simulation is carried out with constant heat flux of $0.24 \mathrm{Kms}^{-1}$ for almost 2 hours of simulation. Table 1 presents some parameters used for LES execution.

Table 1. Parameters for LES execution.

\begin{tabular}{l|l}
\hline Potential temperature & $300 \mathrm{~K}($ vertical domain $)$ \\
\hline Roughness length & $0.16 \mathrm{~m}$ \\
Geostrophic wind $(\mathrm{u}, \mathrm{v})$ & $\left(10 \mathrm{~ms}^{-1}, 0 \mathrm{~ms}^{-1}\right)$ \\
Domain: $(\mathrm{x}, \mathrm{y}, \mathrm{z})$ directions & $\left(5 \times 10^{3} \mathrm{~m}\right) \times\left(5 \times 10^{3} \mathrm{~m}\right) \times\left(2 \times 10^{3} \mathrm{~m}\right)$ \\
Number of grid points & $96 \times 96 \times 96$ \\
\hline
\end{tabular}

Figure 1 shows the evolution for the TKE computed from analytical spectral models M1, M2, M3, M4, and LES results (crosses). Every analytical model mimics the dynamics simulated by LES. Model M4 shows the biggest deviation close to the ground, in comparison to the LES. On the top of boundary layer, M4 and M3 models present the largest disagreement with LES.

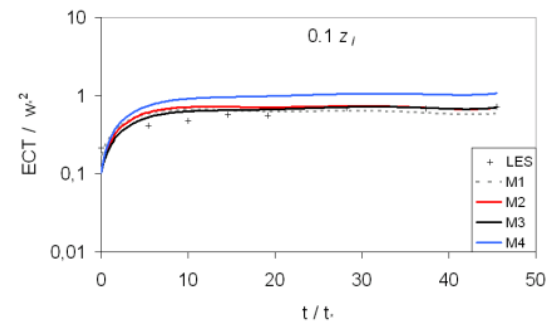

(a)

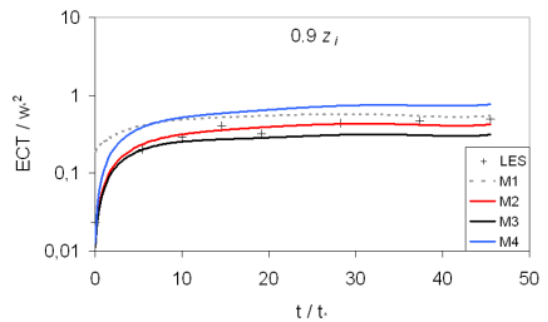

(b)

Figure 1: TKE for the CBL growth simulated by LES and considering four analytical spectral models:

(a) results close to the surface, (b) results for the top of the boundary layer. 
The best agreement with LES results was obtained with M2 model. This model is based on the Taylor's statistical theory for turbulence (Degrazia et al., 1997).

\section{REFERENCES}

MOENG, C-H. A Large-Eddy Simulation model for the study of planetary boundary-layer turbulence. J. Atmos. Sci., 41, 2052-2062, 1984.

STANISIC, M. M. The Mathematical Theory of Turbulence. Springer Verlag, 1988.

CAMPOS VELHO, H. F. A preliminary model for growing of the convective boundary layer. Ciência e Natura, 99-102, 2003.

KRISTENSEN, L, LENSCHOW, D, KIRKEGAARD, P, COURTNEY, M. Courtney M (1989) The spectral velocity tensor for homogeneous boundary-layer turbulence. BoundaryLayer Meteorol., 47: 149-193, 1989.

GOULART, A. G.; DEGRAZIA, G. A.; RIZZA, U. ANFOSSI, D. A theoretical model for the study of convective turbulence decay and comparison with large-eddy simulation data. Boundary-Layer Meteorol., 107: 143-155, 2003.

NUNES, A. B., et al. Morning boundary-layer turbulent kinetic energy by theoretical models. Boundary-Layer Meteorol., 134: 23-39, 2010.

DEgraZIA, G. A., CAMPOS VElHO, H. F., CARVAlHO, J. C. Nonlocal Exchange Coefficients for the Convective Boundary Layer Derived from Spectral Properties. Beitr. Phys. Atmosph., 70, 57-64, 1997.

DEGRAZIA, G. A., ANFOSSI, D. Estimation of the Kolmogorov constant $\mathrm{C}_{0}$ from classical statistical diffusion theory. Atmos. Environ., 32, 3611-3614, 1998.

GOULART, A., et al. An eddy diffusivity derivation for the non-isotropic convective decaying turbulence in the residual layer. In: Air Pollution Modelling and Its Application XVI. (Editors: Borrego and Incecik), Kluwer Academic/Plenum Publishers, 2004. 